\title{
Crianças e adolescentes em situação de vulnerabilidade social no Brasil
}

\author{
Children and adolescents in a situation of social vulnerability in Brazil
}

Niños y adolescentes en situación de vulnerabilidad social en Brasil

Recebido: 09/12/2021 | Revisado: 14/12/2021 | Aceito: 24/12/2021 | Publicado: 04/01/2022

\author{
Kamila Rezende \\ ORCID: https://orcid.org/0000-0003-0070-1504 \\ Universidade Paranaense, Brasil \\ E-mail: kamilaarezendee@hotmail.com \\ Heloisa Cristina Luiz Cappellari \\ ORCID: https://orcid.org/0000-0001-5643-9168 \\ Universidade Paranaense, Brasil \\ E-mail: heloluiz@hotmail.com \\ Lucas Augusto Gaioski Pagani \\ ORCID: https://orcid.org/0000-0001-9396-9133 \\ Universidade Paranaense, Brasil \\ E-mail: lucas.pagani@gmail.com
}

\begin{abstract}
Resumo
O tema do presente trabalho é Crianças e Adolescentes em situação de vulnerabilidade social no Brasil. O objetivo deste é fazer uma análise sobre a situação de vulnerabilidade social em nosso país, através do estudo dos conceitos de vulnerabilidade social, vida em sociedade e sobre o significado de dignidade da pessoa humana, a fim de entender o que é a situação de vulnerabilidade social, bem como as maneiras de detectá-la, os quadros como ela se apresenta em nosso cotidiano. $\mathrm{O}$ tema estudado neste trabalho é de extrema relevância para a sociedade e nosso ordenamento jurídico atual, considerando que, uma vez entendida a situação vivenciada pelas crianças e adolescentes no Brasil, a situação pode ser evitada tanto através de políticas de melhoria da infraestrutura, quando melhora no ambiente escolar e familiar, colaborando ainda para o melhor entendimento da aplicação do Estatuto da Criança e do Adolescente em casos de necessidade de afastamento familiar, como forma de ajudar as crianças e adolescentes que estão em situação de risco e ainda preservar o futuro de nossa nação. Para o desenvolvimento do presente trabalho foram analisadas a doutrina e a legislação vigentes sobre o assunto, e a partir destas foram apresentadas as considerações sobre o tema aqui apresentadas.
\end{abstract}

Palavras-chave: Criança e adolescente; Vulnerabilidade social; Brasil; Políticas públicas; Sociedade.

\begin{abstract}
The theme of this paper is Children and Adolescents in a situation of social vulnerability in Brazil. The objective of the present work is to make an analysis on the situation of social vulnerability in our country, through the study of the concepts of social vulnerability, life in society and on the meaning of human dignity, in order to understand what the situation is of social vulnerability, as well as the ways to detect it, the pictures as it appears in our daily lives. The theme studied in this paper is extremely relevant to society and our current legal system, considering that, once the situation experienced by children and adolescents in Brazil is understood, the situation can be avoided both through policies to improve infrastructure, when improvement in the school and family environment, contributing to a better understanding of the application of the Statute of the Child and Adolescent in cases of need for family leave, as a way to help children and adolescents who are at risk and still preserve the future of our nation. For the development of this work, the current doctrine and legislation on the subject were analyzed, and from these, the considerations on the theme presented here were presented.
\end{abstract}

Keywords: Child and adolescent; Social vulnerability; Brazil; Public policy; Society.

\section{Resumen}

El tema de este trabajo es niños y adolescentes en situación de vulnerabilidad social en Brasil. El objetivo de este trabajo es analizar la situación de vulnerabilidad social en nuestro país, a través del estudio de los conceptos de vulnerabilidad social, la vida en sociedad y el significado de la dignidad humana, con el fin de comprender cuál es la situación. De vulnerabilidad social, así como las formas de detectarlo, los marcos tal y como se presenta en nuestra vida diaria. El tema estudiado en este trabajo es de suma relevancia para la sociedad y nuestro ordenamiento jurídico actual, considerando que, una vez entendida la situación vivida por la niñez y la adolescencia en Brasil, la situación se puede evitar tanto a través de políticas de mejoramiento de infraestructura, como mejoramiento en la escuela y ambiente familiar, contribuyendo también a un mejor entendimiento de la aplicación del Estatuto de la Niñez y Adolescencia en 
casos de necesidad de remoción familiar, como una forma de ayudar a los niños, niñas y adolescentes que se encuentran en riesgo y aún así preservar el futuro de nuestra nación. Para el desarrollo del presente trabajo se analizó la doctrina y legislación vigente en la materia, y a partir de ellas se presentaron las consideraciones sobre el tema que aquí se presentan.

Palabras clave: Niño y adolescente; Vulnerabilidad social; Brasil; Políticas públicas; Sociedad.

\section{Introdução}

A vida em sociedade pode ser definida como uma forma de coexistência em que todos os indivíduos são ligados e multidependentes entre si, além de desenvolverem relações cotidianas. Para que a vida em sociedade seja possível é necessário que algumas regras sejam respeitadas por todos, de forma que a administração, com seu poder coator, cria por meio de leis as regras a serem seguidas por todos, de forma que a liberdade de um indivíduo não prejudique a liberdade de outrem ou vá contra os princípios de nosso Estado Democrático de Direito, instituidor do estado social.

Ao falar no Estado Democrático de Direito não podemos deixar de lado que um dos pilares de nosso Estado é a dignidade da pessoa humana, defendida inclusive constitucionalmente após uma série de fatores históricos que levaram o ser humano a entender que a dignidade deve abranger todo ser vivo, especialmente todo ser humano, independentemente de seu estado de vulnerabilidade perante a sociedade, de seus costumes, credos, raça, cor, idade ou autodeterminação ou de qualquer diferença que venha a apresentar.

Já a vulnerabilidade social, no contexto abrangido por nosso estudo em relação ás crianças e adolescentes, é entendida como um cenário criado pela desigualdade social, da pobreza, da exclusão social, da falta de vínculos afetivos tanto no círculo familiar quanto de amizades, ambiente escolar, entre outros, além da falta de acesso à educação, trabalho, lazer, saúde, alimentação, a falta de recursos materiais mínimos para sobrevivência, a integração muito cedo ao mundo do crime e das drogas, muitas vezes de maneira forçada. Ou seja, a criança ou adolescente que se encontre em situação de vulnerabilidade é aquela totalmente desamparada pela sociedade em geral, indo totalmente em desencontro com o elucidado por nossa Carta Magna quando versa sobre a igualdade entre todos, sobre o fornecimento de condições mínimas para uma sobrevivência digna, e acima de tudo, sobre o respeito à dignidade da pessoa humana.

Dessa forma, considerando a fragilidade que as crianças e adolescentes tem, tanto por sua idade, quanto pela ausência de força ou de autodeterminação, e por estarem em constante desenvolvimento físico e psíquico e em formação de caráter, fora criado o Estatuto da Criança e do Adolescente-ECA, a fim de regulamentar os direitos exercidos por essa parcela vulnerável da população, zelando para que sejam integrados à sociedade e protegidos de todos os perigos que a falta de recursos materiais ou psicológicos pode oferecer.

Este estudo objetiva analisar os conceitos de vulnerabilidade social, vida em sociedade e dignidade da pessoa humana, tecendo uma relação entre eles a fim de entender o que são e como ocorrem as situações de vulnerabilidade na prática, como forma de, por meio da maior conscientização, os direitos dessa parcela da sociedade sejam preservados, zelando pelo futuro da sociedade, que se dá justamente por meio das crianças e adolescentes.

\section{Metodologia}

A metodologia empregada ao presente trabalho foi a pesquisa bibliográfica, considerando que construímos nosso texto através da análise de diversas doutrinas encontradas em livros, revistas cientificas, bibliotecas digitais, teses, pesquisas, artigos e legislação sobre o assunto. Sobre este tipo de metodologia, Medeiros aponta:

A pesquisa bibliográfica é caracterizada pela utilização de fontes secundárias, ou seja, pela identificação e análises dos dados escritos em livros, artigos de revistas, dentre outros. Sua finalidade é colocar o investigador em contato com que já se produzia a respeito do seu tema de pesquisa (Medeiros, 2000, p.40). 
A escolha do tema deu-se em nossa turma de mestrado, quando realizamos uma atividade analítica acerca das garantias para esta fatia da população que desde tão jovem encontra-se em estado de vulnerabilidade, o que despertou nosso interesse e anseio pela pesquisa.

Inicialmente realizamos uma pesquisa vasta sobre o assunto crianças e adolescentes e as mazelas social no brasil, a fim de entender como se dá a situação de vulnerabilidade, levando em conta o período de 2005 a 2021, através de artigos acadêmicos e artigos publicados em revistas, tais como as citadas como referência deste estudo. Para tanto, utilizamos como critérios de inclusão artigos que possuíam a informação sobre a vulnerabilidade.

Posteriormente, realizamos um estudo sobre o que tange as garantias trazidas pelo legislador em torno desse grupo, bem como a doutrina vigente, a fim de que pudéssemos obter um posicionamento mais concreto sobre o pensamento da sociedade em torno da situação enfrentada e tecer uma narrativa acerca de sua definição e resultados específicos para a garantia da segurança destas pessoas em situação de vulnerabilidade social.

\section{Resultados e Discussão}

Desde os primórdios da humanidade o ser humano demonstra necessidade de viver em sociedade, em grupo, de maneira a, além de não estar só, trocar experiências e trabalhos que beneficiem não apenas a ele mesmo mas a todos os seus próximos, sendo a necessidade de conexão inerente ao ser humano, e a vida em sociedade necessária para o bem estar da raça humana.

Segundo Arendt (2005), a sociedade, por sua vez, é condicionadora e condicionante, ou seja, determina o comportamento dos indivíduos que ali vivem, porém, também é condicionada pelos indivíduos que a formam.

Vivemos em um Estado Democrático de Direito que tem como princípios a defesa dos direitos fundamentais, da vida, da honra, da segurança, da imagem e do domicilio, considerando a importância da defesa destes para o convívio em sociedade e também para que tantos outros direitos sejam resguardados através de sua defesa.

Ingo Wolfgang Sarlet ressalta a importância da acolhida dos direitos fundamentais pela Constituição Federal brasileira de 1988, já que as constituições anteriores não a retratavam.

“A acolhida dos direitos fundamentais sociais em capítulo próprio no catálogo dos direitos fundamentais, ressalta, por sua vez, de forma incontestável sua condição de autênticos direitos fundamentais, já que nas cartas anteriores os direitos sociais encontravam-se positivados no capítulo da ordem econômica e social, sendo-lhes, ao menos em princípio e ressalvadas algumas exceções, reconhecido caráter meramente programático". (SARLET, 2012)

Este conceito se estende a todos os indivíduos que fazem parte do nosso estado como cidadãos, sendo inclusive garantidos constitucionalmente, sendo dever do estado.

Neste contexto, podemos definir os Direitos Humanos como sendo direitos inerentes a todas as pessoas, independente de raça, religião, crença política ou religiosa, cor, sendo todos por eles englobados pelo simples fato de pertencerem a raça humana, pois diferentemente das demais espécies, o ser humano deve ter seus direitos resguardados.

A criação e proteção legal destes direitos tão importantes a existência humana se deu justamente a fim de prevenir e acabar com qualquer conduta abusiva, lesiva, vexatória, que remeta a tortura, maus tratos, ou atente contra a dignidade de indivíduos humanos, bem como tratamento desigual entre indivíduos humanos, como forma de aprimoramento do convívio em sociedade e respeito a todos como seres humanos portadores de direitos constitucionais.

O contexto de surgimento destes direitos ocorreu principalmente após a Segunda Guerra Mundial, quando o mundo todo, horrorizado com o cenário panorâmico mundial de tortura e ofensa a humanidade causado pelas guerras, resolveu adotar a Declaração Universal de Direitos Humanos, documento este assinado pelos mais diversos representantes de todo o mundo e adotado pela Organização Das Nações Unidas como órgão fiscalizador, a fim de que não exista mais na história da humanidade 
qualquer conduta semelhante à ocorrida no passado, que fira a integridade física ou psicológica do ser humano.

Nossa Constituição Federal, advinda no período pós Declaração Universal de Direitos Humanos, é considerada uma constituição cidadã, devido a defesa aos direitos humanos que traz em seu texto legal, possibilitando a todos um convívio igualitário e a proteção a vida e aos direitos de todos de maneira homogênea, sem distinções entre seres humanos, primando unicamente pelo respeito a vida de todos os seres humanos de maneira igualitária.

Segundo Luís Flavio Sapori (2007):

“A manutenção da ordem pública, ou seja, a defesa de um estado em que todos possam coexistir em paz e zelando pelo bem-estar geral, respeitando entre si e respeitando as premissas da administração, é um dos principais bens coletivos da sociedade humana."

Consagrando expressamente, no título dos princípios fundamentais, a dignidade da pessoa humana como um dos fundamentos do nosso Estado democrático (e social) de Direito (art. $1^{\circ}$, inc. III, da CF), o nosso Constituinte de 1988 - a exemplo do que ocorreu, entre outros países, na Alemanha -, além de ter tomado uma decisão fundamental a respeito do sentido, da finalidade e da justificação do exercício do poder estatal e do próprio Estado, reconheceu categoricamente que é o Estado que existe em função da pessoa, e não o contrário, já que o ser humano constitui a finalidade precípua, e não meio da atividade estatal.(Sarlet, 2012).

O próprio texto da nossa Constituição Federal, em seu artigo primeiro, demonstra que nosso país constitui-se em um Estado Democrático de Direito que zela pela dignidade da pessoa humana, deixando claro que os objetivos deste estado são de atender as necessidades da população, visando a convivência em uma sociedade justa, que zele pela liberdade, tranquilidade, paz, respeito aos direitos fundamentais de todos os cidadãos que a integram.

Art. $1^{\circ}$ A República Federativa do Brasil, formada pela união indissolúvel dos Estados e Municípios e do Distrito Federal, constitui-se em Estado Democrático de Direito e tem como fundamentos:

I - A soberania;

II - A cidadania;

III - a dignidade da pessoa humana;

IV - Os valores sociais do trabalho e da livre iniciativa;

V - O pluralismo político.

Parágrafo único. Todo o poder emana do povo, que o exerce por meio de representantes eleitos ou diretamente, nos termos desta Constituição. (Brasil, 1988).

Referido diploma legal apresenta em seu artigo quinto que todos são iguais perante a lei, sem distinções, e que são invioláveis a intimidade, a vida privada, a honra e a imagem das pessoas, como forma de proteção aos direitos fundamentais de todos.

Art. $5^{\circ}$ Todos são iguais perante a lei, sem distinção de qualquer natureza, garantindo-se aos brasileiros e aos estrangeiros residentes no País a inviolabilidade do direito à vida, à liberdade, à igualdade, à segurança e à propriedade, nos termos seguintes:

III - ninguém será submetido à tortura nem a tratamento desumano ou degradante;

$\mathrm{X}$ - São invioláveis a intimidade, a vida privada, a honra e a imagem das pessoas, assegurado o direito a indenização pelo dano material ou moral decorrente de sua violação; (Brasil,1988).

A dignidade da pessoa humana constitui garantia máxima do estado desde os primórdios da criação do Estado Democrático de Direito e principal princípio defendido pela administração, considerando sua importância para a formação de tantos outros princípios fundamentais constitucionais e as imensuráveis garantias a vida humana que surgiram desde sua criação, possibilitando que a vida em sociedade seja mais tranquila e respeitosa para todos.

Alexandre de Morais (2005), em seu livro Direito Constitucional, conceitua a dignidade da pessoa humana como sendo 
uma unidade de direitos e garantias fundamentais, inerente às personalidades humanas, in verbis:

Ao Estado cabe o dever de garantir a justiça e direitos de liberdade individual. A dignidade da Pessoa Humana atribui unidade aos direitos e garantias fundamentais, inerente às personalidades humanas afastando a ideia de predomínio das concepções transpessoalistas de Estado e Nação, em função da liberdade individual. A dignidade é um valor espiritual e moral intrínseco da pessoa, que se manifesta singularmente na sua autodeterminação consciente e responsável, trazendo consigo a pretensão ao respeito das demais pessoas, edificando um mínimo invulnerável que todo estatuto jurídico deve assegurar, de modo que, excepcionalmente, possam ser feitas limitações ao exercício dos direitos fundamentais, todavia sem menosprezar o merecimento das pessoas enquanto seres humanos.

Neste toar, pode-se definir a dignidade da pessoa humana como sendo um englobamento de todos os direitos percebidos por um indivíduo, uma forma de melhorar o convívio em sociedade através do respeito à dignidade de cada ser humano, devendo esta ser respeitada por todos, como forma de conservar a vida em sociedade e preservar os direitos de todos.

No mesmo contexto, em 1989, a Organização das Nações Unidas criou a Convenção sobre os direitos da Criança, introduzindo no panorama mundial que a criança e ao adolescente, da mesma maneira que qualquer indivíduo, devem ser tratados como seres humanos, possuindo os mesmos direitos que qualquer adulto já formado e ainda devendo ser levado em consideração o fato de ser uma pessoa em constante desenvolvimento, possuindo certas prioridades no que tange a políticas públicas, em razão de usa necessidade.

Entretanto, apesar da pregação sobre igualdade de direitos e dignidade para todos os seres humanos, é inerente ao ser humano que algumas diferenças sociais surjam em meio a vida em sociedade, em decorrência das diferenças que cada indivíduo apresenta e também das divisões sociais existentes, geradas pelo sistema capitalista, politicas capitalistas, pela falta de infraestrutura do Estado em geral, falta de oportunidade entre as classes sociais.

Dessa maneira determinados grupos sociais ou indivíduos tendem a ser mais vulneráveis que os demais, ou seja, são mais fragilizados política ou juridicamente, estando mais suscetíveis a incorrer em danos físicos ou morais em decorrência de sua condição.

Segundo Liborio e Souza (2004), “a vulnerabilidade acontece apenas quando o risco está presente e quando o indivíduo está exposto a diversas situações que interferem no seu processo de desenvolvimento social, psicológico e físico".

A vulnerabilidade é social porque são os mais pobres que enfrentam as maiores dificuldades para se adaptarem às intempéries extremas dadas as condições de fragilidade em que se encontram (Ribeiro, 2008).

Segundo Beck (2006), “a sociedade contemporânea cria riscos e parece acostumar- se a eles".

Ainda, de acordo com Margulis \& Urresti (1996):

“As categorias adolescências e juventudes são construções culturais e sociais, que têm uma base material vinculada à idade. Essa facticidade dos ciclos etários apresenta um modo particular de estar no mundo em sua temporalidade, com distâncias e durações diferenciadas. A condição etária aparece em todas as sociedades como um dos principais eixos ordenadores das políticas públicas e das ações sociais".

Dentre estes grupos destaca-se o grupo das crianças e adolescentes, podendo estes ser entendidos por indivíduos que ainda estão em formação de caráter e de sua estrutura física e mental, em decorrência da idade. São considerados crianças os indivíduos que possuam até 10 (dez) anos de idade, e adolescentes indivíduos entre os 10 (dez) e os 20 (vinte) anos de idade, de acordo com a Organização Mundial de Saúde (OMS). Já de acordo com o Estatuto da Criança e do Adolescente (ECA), a primeira fase vai até os 12 (doze) anos e a segunda, dos 12 (doze) aos 18 (dezoito) anos.

De acordo com Tomita (2001), os adolescentes vivem uma constante busca para encontrar sua real personalidade, manifestando comportamentos extremos e, em determinados momentos, mostram-se negligentes com os cuidados à saúde.

Ainda, afirma Margulis \& Urresti (1996), que: 
“A população adolescente e jovem vive uma condição social que é única: uma mesma geração, num mesmo momento social, econômico, político e cultural do seu país e do mundo. Ou seja, a modalidade de ser adolescente e jovem depende da idade, da geração, da moratória vital, da classe social e dos marcos institucionais e de gênero presentes em dado contexto histórico e cultural"

Conforme Mielnik (2010)," adolescentes não formam um grupo homogêneo, pois cada um deles possui características e personalidades diferentes."

Nesse sentido, a atenção integral à saúde dos adolescentes e jovens apresenta-se como um desafio, por tratar-se de um grupo social em fase de grandes e importantes transformações psicobiológicas articuladas a um envolvimento social e ao redimensionamento da sua identidade e dos novos papéis sociais que vão assumindo (Ayres \& França júnior, 1996).

A definição sobre vulnerabilidade remete à ideia de fragilidade e de dependência, que se conecta à situação de crianças e adolescentes, principalmente os de menor nível socioeconômico. Devido à fragilidade e dependência dos mais velhos, esse público torna-se muito submisso ao ambiente físico e social em que se encontra. Em determinadas situações, o estado de vulnerabilidade pode afetar a saúde, mesmo na ausência de doença, mas com o abalo do estado psicológico, social ou mental. (SIERRA, 2006).

Outrossim, Abramovay \& Castro \& Pinheiro \& Lima \& Martinelli (2002), entendem que:

"As crianças e adolescentes que se encontram em situação de vulnerabilidade social são aquelas que vivem negativamente as consequências das desigualdades sociais; da pobreza e da exclusão social; da falta de vínculos afetivos na família e nos demais espaços de socialização; da passagem abrupta da infância à vida adulta; da falta de acesso à educação, trabalho, saúde, lazer, alimentação e cultura; da falta de recursos materiais mínimos para sobrevivência; da inserção precoce no mundo do trabalho; da falta de perspectivas de entrada no mercado formal de trabalho; da entrada em trabalhos desqualificados; da exploração do trabalho infantil; da falta de perspectivas profissionais e projetos para o futuro; do alto índice de reprovação e/ou evasão escolar; da oferta de integração ao consumo de drogas e de bens, ao uso de armas, ao tráfico de drogas."

Assim, como forma de tentar conter a diferença social e a vulnerabilidade existente com relação à criança e o adolescente, foi sancionado no Brasil em 13 de julho de 1990 o Estatuto da Criança e do Adolescente (ECA), por meio da lei n. 8.069, que se baseia na proteção integral aos direitos das crianças e adolescentes, objetivando proporcionar proteção à vida, a saúde destas minorias, entre outras prerrogativas necessárias para que seja garantida a dignidade da pessoa humana entre eles.

O ECA (1990) define as crianças e adolescentes como sujeitos de direito, conforme pode-se observar em seu artigo $4^{\circ}$ :

Art. $4^{\circ}$ É dever da família, da comunidade, da sociedade em geral e do poder público assegurar, com absoluta prioridade, a efetivação dos direitos referentes à vida, à saúde, à alimentação, à educação, ao esporte, ao lazer, à profissionalização, à cultura, à dignidade, ao respeito, à liberdade e à convivência familiar e comunitária. Parágrafo único. A garantia de prioridade compreende: a) primazia de receber proteção e socorro em quaisquer circunstâncias; b) precedência de atendimento nos serviços públicos ou de relevância pública; c) preferência na formulação e na execução das políticas sociais públicas; d) destinação privilegiada de recursos públicos nas áreas relacionadas com a proteção à infância e à juventude.

Referido dispositivo legal ainda versa que nenhuma criança ou adolescente será privado de seus direitos ou poderá têlos negligenciados. "Art. $5^{\circ}$ Nenhuma criança ou adolescente será objeto de qualquer forma de negligência, discriminação, exploração, violência, crueldade e opressão, punido na forma da lei qualquer atentado, por ação ou omissão, aos seus direitos fundamentais." (ECA, 1990).

O Estatuto dispõe ainda que casos de abuso sexual, mais tratos, opressão impostos pelos pais ou responsáveis, a autoridade judiciaria poderá afastar o agressor da moradia comum, havendo inclusive medidas de proteção para casos de alcoólatras e toxicômanos na família, como maneira de proteger as crianças e adolescentes de qualquer situação que lhes cause 
algum trauma físico ou psicológico, justamente a fim de promover os direitos fundamentais destes indivíduos.

Mesmo que a disposição do ECA tenha trazido diversas mudanças positivas, trazendo mais garantia de direitos e conforto as crianças e adolescentes, ainda não era o suficiente, persistindo as transgressões a direitos deste grupo, e desta maneira, persistindo a vulnerabilidade da minoria, de forma que foi necessário que a administração desse vida a um órgão público e autônomo, capaz de fiscalizar o cumprimento dos direitos e deveres com relação aos menores, assim surgindo o Conselho Tutelar, de caráter permanente e atuando em âmbito municipal, através de funções especificas e eletivas entre os indivíduos do município, a fim de atender casos de transgressões a direitos e garantir o cumprimento do bem estar a minoria.

As atribuições deste Conselho estão reguladas no artigo 136 do ECA (1990). Veja-se:

Art. 136- São atribuições do Conselho Tutelar: atender as crianças e adolescentes nas hipóteses previstas nos arts. 98 e 105, aplicando as medidas previstas no art. 101, I a VII; II - atender e aconselhar os pais ou responsável, aplicando as medidas previstas no art. 129, I a VII; III - promover a execução de suas decisões, podendo para tanto: a) requisitar serviços públicos nas áreas de saúde, educação, serviço social, previdência, trabalho e segurança; b) representar junto à autoridade judiciária nos casos de descumprimento injustificado de suas deliberações. IV - encaminhar ao Ministério Público notícia de fato que constitua infração administrativa ou penal contra os direitos da criança ou adolescente; V encaminhar à autoridade judiciária os casos de sua competência; VI - providenciar a medida estabelecida pela autoridade judiciária, dentre as previstas no art. 101, de I a VI, para o adolescente autor de ato infracional; VII - expedir notificações; VIII - requisitar certidões de nascimento e de óbito de criança ou adolescente quando necessário; IX - assessorar o Poder Executivo local na elaboração da proposta orçamentária para planos e programas de atendimento dos direitos da criança e do adolescente; $\mathrm{X}$ - representar, em nome da pessoa e da família, contra a violação dos direitos previstos no art. 220, $\S 3^{\circ}$, inciso II, da Constituição Federal ; XI - representar ao Ministério Público, para efeito das ações de perda ou suspensão do pátrio poder. XI - representar ao Ministério Público para efeito das ações de perda ou suspensão do poder familiar, após esgotadas as possibilidades de manutenção da criança ou do adolescente junto à família natural. (Redação dada pela Lei $\mathrm{n}^{\circ}$ 12.010, de 2009) Vigência XII - promover e incentivar, na comunidade e nos grupos profissionais, ações de divulgação e treinamento para o reconhecimento de sintomas de maus-tratos em crianças e adolescentes. (Incluído pela Lei $n^{\circ}$ 13.046, de 2014) Parágrafo único. Se, no exercício de suas atribuições, o Conselho Tutelar entender necessário o afastamento do convívio familiar, comunicará incontinenti o fato ao Ministério Público, prestando-lhe informaçães sobre os motivos de tal entendimento e as providências tomadas para a orientação, o apoio e a promoção social da família.

A administração ainda buscou por maneiras subsidiárias de garantir o mínimo material necessário ao bem estar e ao crescimento saudável desta minoria, tendo lançado programas como bolsa família e bolsa escola, que são programas de estimulo financeiro a famílias consideradas de baixa renda, ou seja, que não conseguem prover seu próprio sustento, a fim de diminuir o índice de crianças e adolescentes trabalhando, ou envolvidos em crimes devido às más condições financeiras e sociais em que estejam inseridos, além do programa saúde na escola, que cultiva projetos relacionados a área da saúde, como exames médicos, acompanhamento de nutricionista, dentistas, suplementos alimentares e demais cuidados necessários ao bom desenvolvimento e que essas minorias muitas vezes deixam de receber em razão de sua condição social e monetária, como uma maneira de prevenção de doenças e de zelar pela saúde pública.

No entendimento de Moreira Neto (1988) "se as garantias proporcionadas pela segurança pública são eficientes e satisfatórias, tem-se mantida a ordem pública".

Para José Afonso da Silva (2009), “ordem pública será uma situação de pacífica convivência social, isenta de ameaça de violência ou de sublevação que tenha produzido ou que supostamente possa produzir a curto prazo, a prática de crimes".

Ainda, há que ser considerada a situação de vulnerabilidade dentro dos mais diversos âmbitos em que a criança ou adolescente esteja envolvida, como no âmbito familiar, escolar, de amizades, etc., de forma que nossa Carta Magna trata em seu artigo 227 sobre o princípio do melhor interesse da criança e do adolescente.

Art. 227 É dever da família, da sociedade e do Estado assegurar à criança, ao adolescente e ao jovem, com absoluta prioridade, o direito à vida, à saúde, à alimentação, à educação, ao lazer, à profissionalização, à cultura, à dignidade, ao 
respeito, à liberdade e à convivência familiar e comunitária, além de colocá-los a salvo de toda forma de negligência, discriminação, exploração, violência, crueldade e opressão. (BRASIL, 1988).

Referido princípio possui status de direito fundamental, considerando ser texto constitucional, devendo ser respeitado e seguido por todos, até mesmo pelos julgadores, e pelo próprio poder público, a fim de respeitar estas minorias em qualquer situação em que se apresentem.

O autor Fachin, (2012) versa que:

"O melhor interesse da criança assume um contexto, que em sua definição o descreve como "basic interest", como sendo aqueles essenciais cuidados para viver com saúde, incluindo a física, a emocional e a intelectual, cujos interesses, inicialmente são dos pais, mas se negligenciados o Estado deve intervir para assegura-los.

Segundo a UNICEF (2011) devem ser convocados o Estado, a sociedade brasileira e as famílias a garantirem para cada um desses meninos e meninas o direito de viver essa etapa de sua vida sob a lógica da equidade.

Dessa forma, o legislador deixa aberta a possibilidade em casos em que os pais não possuem condições materiais ou psíquicas de prover o sustento e a criação dos filhos, bem como abusadores ou desrespeitosos e agressivos física ou verbalmente, que lhes seja destituído o poder familiar, retirando a criança ou adolescente do âmbito familiar e a levando para um abrigo público, onde ela receberá todo o aparato físico, psicológico e material necessário para seu desenvolvimento saudável e longe de qualquer perigo.

A família é a fonte primaria que um indivíduo recebe de proteção, afeto, socialização, sendo também responsável pela base do desenvolvimento do jovem, de forma que seu papel é importantíssimo e deve ser zelado com responsabilidade a fim de não causar nenhum dano que gere um novo ciclo de vulnerabilidade.

O ambiente não é determinador de um desenvolvimento emocional saudável, mas o facilitador das condições saudáveis ao processo de amadurecimento (Oliveira, 2003).

De igual forma o Estado intervém, através de seus órgãos, no ambiente escolar e qualquer ambiente que apresente ameaça a esta minoria, dando total suporte para que cresçam em harmonia.

Entretanto, apesar da legislação especifica e da existência de órgãos próprios e capacitados a fim de atendes apenas demandas desta natureza, o mais importante é que toda a população tome consciência de que as crianças e adolescentes constituem minoria vulnerável que deve ser auxiliada, entendida e protegida, apenas desta forma a vida em sociedade será preservada, e os direitos fundamentais, especialmente o da dignidade da pessoa humana, serão resguardados.

É necessária uma colaboração do poder público, dos órgãos especializados, das escolas, famílias e da população em geral para fazer valer todos os direitos que foram conquistados por esta minoria da população, amparando estes jovens e possibilitando uma pacificação de condutas e regulação da realidade social, a fim de tentar conter a situação de vulnerabilidade social enfrentada por esta parcela da população desde sempre.

\section{Considerações Finais}

Através dos fatos analisados no presente estudo podemos concluir que a vida em sociedade existe desde os primórdios da existência humana, tendo acompanhado sua evolução em razão da necessidade da espécie de se manter conectada com seus semelhantes, além das necessidades mutuas, trocas de objetos ou atos favoráveis a um indivíduo ou a sociedade em geral, e do senso de sobrevivência em grupo.

Desta forma, com o surgimento do estado democrático de direito, surgiram normas advindas da administração a ser respeitadas por todos os indivíduos integrantes do estado, contendo direitos e deveres que devem ser seguidos, de forma que o 
exercício da liberdade e dos direitos de um indivíduo não venha a lesionar a liberdade ou os direitos de outrem, nem vá contra as premissas do poder público.

Por sua vez, surgiu entre os direitos fundamentais a dignidade da pessoa humana, após um vasto histórico de lutas e agressões físicas, tortura e atos considerados impróprios realizados entre seres humanos ao longo dos tempos, especialmente no período pós guerras, sendo está incluída em nossa Carta Magna (1988), como forma de garantir que todo ser humano terá tratamento igualitário em respeito à sua vida, sua honra, imagem, entre outros direitos, sendo tratado com o respeito necessário.

Ademais, apesar de todo o aparato em defesa da igualdade, continuaram existindo minorias, dentre elas, as crianças e adolescentes, vulneráveis ante os demais seres humanos em razão de sua pouca idade, formação intelectual e física, necessitando de maior apoio do estado e de toda a sociedade em sua proteção. Assim, fora criado o Estatuto da Criança e do Adolescente (1990), como maneira de regular sobre os direitos desta minoria que se encontra em situação de vulnerabilidade social, dispondo sobre seus direitos, deveres e sobre a criação de órgãos aptos a somente trabalhar nestes casos.

Apesar de todo o aparato estatal a fim de resguardar os direitos das crianças e adolescentes, a principal conclusão a que se chega com este estudo é de que deve a sociedade se fragilizar pela situação e agir de acordo com as normas legais estabelecidas, colaborando para a maior integração e proteção desta minoria, e respeitando seus direitos e suas diferenças com os demais, a fim de, desta maneira, além de garantir o saudável crescimento a estes jovens que são o futuro, perpetuar a vida em sociedade e o futuro da nação.

Cumprimos o objetivo do presente trabalho, qual seja, entendemos como se dá a situação de vulnerabilidade incluindo crianças e adolescentes no Brasil, bem como as medidas tomadas pelo serviço público com a elaboração de leis e projetos a fim de diminuir a situação.

Para trabalhos futuros, sugerimos a realização de pesquisa bibliográfica e da legislação sobre o assunto, bem como pesquisa de campo a fim de averiguar a realidade das crianças e adolescentes que se encontram em situação de vulnerabilidade no Brasil.

\section{Referências}

Abramovay, M., Castro, G. M., Pinheiro, L. C., Lima, F. S., Martinelli, C.C. (2002). Juventude, violência e vulnerabilidade social na América Latina: desafios para políticas públicas. Brasília: UNESCO/ BID.

Arendt, H. (2005) A Condição Humana. Rio de Janeiro, Forense Universitária.

Ayres, J. R. C. M., França J, I. Jr. Saúde do Adolescente. In: Scharaiber, L. B., Nemes, M. I. B., Gonçaves, R. B. M. (1996). Saúde do Adulto. Programas e Ações na Unidade Básica. São Paulo: Ed. Hucitec.

Beck, U. (2006). La sociedad del riesgo: hacia una nueva modernidad. Barcelona: Paidós.

Brasil. Constituição (1988). Constituição da República Federativa do Brasil, 1988. Brasília: Senado Federal, Centro Gráfico.

Brasil. Lei no 8.069, de 13 de julho de 1990. Estatuto da Criança e do Adolescente. http://www.planalto.gov.br/ccivil_03/leis/18069.htm.

Fachin, L. E. (2012). Direito à visitação. In: Carta Forense. http://www.cartaforense.com.br/v1/index.php?id=entrevista\&identrevista=46

Libório, R.M.C., Souza, S.M.G. (2004). A exploração sexual de crianças e adolescentes no Brasil: reflexões teóricas, relatos de pesquisas e intervenções psicossociais. Casa do Psicologo Livraria e editora Ltda.

Margulis, M., Urresti, M. (1996). La Juventud es más que una Palabra. Buenos Aires: Biblos.

Mielnik, I. (2010). Os adolescentes: conceito, dinâmica e orientação do adolescente. São Paulo: IBRASA.

Morais, A. (2005). Direito Constitucional. 17. ed. São Paulo: Atlas.

Moreira, D. F. N. (1988). Revisão doutrinária dos conceitos de ordem pública e segurança pública. Revista de Informação Legislativa. Brasília.

Oliveira, E.D. (2003). A teoria do amadurecimento de D. W. Winnicott. Rio de Janeiro: Imago. 
Research, Society and Development, v. 11, n. 1, e18611124587, 2022

(CC BY 4.0) | ISSN 2525-3409 | DOI: http://dx.doi.org/10.33448/rsd-v11i1.24587

Ribeiro, W. C. (2010). Riscos e vulnerabilidade urbana no Brasil. Scripta Nova. Revista Electrónica de Geografía y Ciencias Sociales. Barcelona: Universidad de Barcelona.

SAPORI, L. F. (2007). Segurança Pública no Brasil - Desafios e perspectivas. Rio de Janeiro: FGV.

SARLET, I. W. (2010). Dignidade da Pessoa Humana e Direitos Fundamentais na Constituição Federal de 1988. 8.ed. ver. atual. e ampl. - Porto Alegre: Livraria do Advogado Editora.

Sierra, V.M., Mesquita, W. A. (2006). Vulnerabilidades e fatores de risco na vida de crianças e adolescentes. São Paulo em Perspec.

Silva, J. A. (2009). Comentário contextual à constituição. 6. ed. atual. até a Emenda Constitucional 57, de 18.12.2008. São Paulo: Malheiros.

Tomita, N. E., et al. (2001). Oral health education for teenagers: development of dynamics methods. Rev Fac Odontol Bauru.

UNICEF. (2011). O direito de ser adolescente: oportunidade para reduzir vulnerabilidades e superar desigualdades / Fundo das Nações Unidas para a Infância. - Brasília, DF: UNICEF. 